\title{
Complete Penetrance of Creutzfeldt- Jakob Disease in Libyan Jews Carrying the E200K Mutation in the Prion Protein Gene
}

\author{
Serena Spudich,* James A. Mastrianni,* Margaret Wrensch, ${ }^{\dagger}$ \\ Ruth Gabizon, ${ }^{\neq}$Zeev Meiner,* Irit Kahana, ${ }^{\neq}$Hana Rosenmann, ${ }^{\neq}$ \\ Esther Kahana, ${ }^{*}$ and Stanley B. Prusiner*\$ \\ Departments of *Neurology, ${ }^{*}$ Biochemistry and Biophysics, and \\ ${ }^{\dagger}$ Epidemiology and Biostatistics, University of California, San \\ Francisco, California, U.S.A. \\ ${ }^{\ddagger}$ Department of Neurology, Hadassah University Hospital, Ein Karem, \\ Jerusalem, Israel
}

\begin{abstract}
Background: Creutzfeldt-Jakob disease (CJD) is a prion disease which is manifest as a sporadic, inherited, and transmissible neurodegenerative disorder. The mean age at onset of CJD is $\sim 60$ years, and as such, many people destined to succumb undoubtedly die of other illnesses first. The delayed onset of CJD has complicated the analysis of inherited forms of the illness and led to the suggestion that mutations in the prion protein $(\mathrm{PrP})$ gene are necessary but not sufficient for prion disease despite genetic linkage; indeed, an environmental factor such as a ubiquitous virus has been proposed as a second necessary factor.
\end{abstract}

Materials and Methods: To examine what appeared to be incomplete penetrance, we applied a life-table analysis to clinical and pedigree data from a cluster population of Libyan Jews in which the E200K mutation is prevalent. The study population included 42 affected and 44 unaffected members of 13 Libyan Jewish families, all of whom possessed the E200K mutation.

Results: The calculated value using life table analysis is 0.77 at age 70 which increases to 0.89 if a mutation carrier survives to age 80 and 0.96 if age 80 is surpassed. Conclusions: These data argue that the E200K mutation alone is sufficient to cause prion disease and does so in an age-dependent manner.

\section{INTRODUCTION}

The human prion diseases include kuru, CreutzfeldtJakob disease (CJD), Gerstmann-Sträussler-Scheinker disease (GSS) and fatal familial insomnia (1). These CNS degenerative diseases present as sporadic, inherited, and infectious disorders. CJD is frequently characterized by progressive dementia

Address correspondence and reprint requests to: Stanley B. Prusiner, Department of Neurology, HSE-781, University of California, San Francisco, CA 94143-0518, U.S.A. in association with variable degrees of myoclonus, extrapyramidal, pyramidal, and cerebellar signs, and an electroencephalogram showing periodic discharges. The worldwide incidence of CJD is approximately 1 per $10^{6}$ population/year. For many years geographic clusters of CJD were attributed to common source exposure to a "slow virus" but the discovery of a PrP gene point mutation genetically linked to GSS (2) led to the demonstration that such clusters were due to inherited prion diseases $(3,4)$. The largest such focus found is among a 
population of Libyan Jews, many of whom now reside in Israel. Within this community, the prevalence of CJD is about 100 per $10^{6}$ population (5).

For nearly two decades, the high incidence of CJD among Libyan Jews was attributed to the consumption of lightly cooked sheep brain (6) or sheep eyeballs (7) contaminated with the "scrapie virus." Scrapie is a naturally occurring prion disease of sheep and goats. The identification of a mutation in the PrP gene resulting in the nonconservative substitution of Lys for Glu at position 200 (E200K) in patients with the disease and some healthy members of the families suggested an alternative explanation $(3,4)$. Genetic linkage of the E200K mutation with a lod score of $>4.8$ established that this illness is an inherited prion disease (8).

The penetrance of the E200K mutation has been considered incomplete, a conclusion supported by the observation that some mutation carriers have lived well beyond the "typical age" at which prion diseases occur in this population. A previous estimate of disease penetrance in E200K mutation carriers was 0.56 (9). This number was obtained by comparing the number of CJD cases observed with that which would be expected based on the presence of the mutation. This approach failed to account for the fact that certain subjects had not yet reached an age at which they were likely to manifest the disease, or that some subjects may have died from causes other than CJD before reaching the age range at which they are at higher risk.

This low penetrance value gave rise to the notion that a mutation of the PrP gene was not sufficient to cause disease (9). In fact, it was suggested that the mutation only confers a predisposition to disease and that exposure to some environmental factor such as the ubiquitous "scrapie virus" is required to produce CJD (10-13).

Because of the need for accurate estimates of penetrance in family counseling, we felt it important to reassess the issue of penetrance using a life table analysis (14-16). This actuarial method of analysis predicts survival without the development of disease. It uses a distribution of age at disease onset to derive the probability of survival without disease at any point along the time scale while accounting for the natural rate of death or loss to follow-up from other causes. During the preparation of this manuscript, some of the investigators who made the original estimate of a penetrance value of 0.56 used this same method of analysis on another cohort of
E200K carriers and have now revised their estimates to a higher penetrance of 0.94 (17).

\section{MATERIAL AND METHODS}

\section{Study Subjects}

Subjects were 42 Libyan Jewish CJD patients from 13 families and 44 additional unaffected mutation carriers who are first or second degree relatives of the affected patients. The presence of the E200K mutation was determined in all healthy carriers by allele specific oligonucleotide hybridization, as described elsewhere (18). Specimens were available on 29 of the CJD patients for mutation detection, and the remaining 13 were deduced to be obligate carriers, by pedigree analysis. The appearance of CJD was denoted by typical symptoms of rapidly progressive dementia, myoclonus, and periodic discharges on EEG. Five subjects were pathologically confirmed. All patients clinically diagnosed with CJD died within 13 months (average duration \pm standard deviation $=4.6 \pm 3.3$ months), supporting the diagnosis in those cases that did not go to autopsy. Those with questionable disease patterns (i.e., duration greater than 15 months in the absence of a pathologic diagnosis, or lack of more than one of the above clinical criteria) have been excluded from analysis, as were patients with recent onset "possible CJD" who were still alive at the time of study. This approach avoids attributing unrelated disease to the development of CJD in an E200K carrier and thereby conservatively estimates penetrance.

\section{Statistical Analysis}

The "life table" method of analysis uses a distribution of age at onset of disease to derive the probability of survival without disease at any point along the time scale $(14,19)$. A function is applied to the data that identifies the probability of surviving without developing CJD to a given age interval, while accounting for those who were too young to reach the interval, as well as those that died from other causes during the interval. Parameters used to calculate the various probabilities and the description of relevant equations are listed in Table 1. 
TABLE 1. Life table analysis data

\begin{tabular}{ccccccccc}
\hline Interval & $\begin{array}{c}\text { Age Range } \\
\text { (years) }\end{array}$ & $\begin{array}{c}\text { \# of } \\
\text { Carriers }\end{array}$ & $\begin{array}{c}\text { Not Yet } \\
\text { of Age } \mathbf{A g}^{a}\end{array}$ & $\begin{array}{c}\text { Deaths } \\
\text { (CJD) }\end{array}$ & $\begin{array}{c}\text { Deaths } \\
\text { (non-CJD) }\end{array}$ & $\boldsymbol{Q}_{\boldsymbol{i}}$ & $\boldsymbol{S}_{\boldsymbol{i}}$ & $\mathbf{1}-\boldsymbol{S}_{\boldsymbol{i}}$ \\
\hline 1 & $<30$ & 79 & 4 & 0 & 0 & 1.00 & 1.00 & 0.00 \\
2 & $31-40$ & 75 & 6 & 1 & 0 & 0.99 & 0.99 & 0.01 \\
3 & $41-50$ & 68 & 10 & 9 & 0 & 0.86 & 0.85 & 0.15 \\
4 & $51-60$ & 49 & 10 & 16 & 0 & 0.64 & 0.55 & 0.45 \\
5 & $61-70$ & 23 & 4 & 12 & 0 & 0.43 & 0.23 & 0.77 \\
6 & $71-80$ & 7 & - & 3 & 2 & 0.50 & 0.11 & 0.89 \\
7 & $>80$ & 2 & - & 1 & 1 & 0.33 & 0.04 & 0.96 \\
\hline
\end{tabular}

$Q_{i}$ is the probability that a CJD gene carrier has not become affected by the end of age interval (i), and the "life table" estimate of $Q_{i}$ is:

$$
Q_{i}=\frac{n_{i}-d_{i}-c_{i} / 2}{n_{i}-c_{i} / 2}
$$

where $n_{i}=$ \# gene carriers alive at the beginning of the $i^{\text {th }}$ interval, $c_{i}=\#$ of individuals "censored", or removed from the study during the $i^{\text {th }}$ interval, ${ }^{a}$ and $d_{i}=\#$ individuals affected with CJD during the $i^{\text {th }}$ interval. The cumulative probability $\left(S_{i}\right)$ of surviving from the beginning of the study to the end of the $i^{\text {th }}$ interval without developing CJD is calculated by:

$$
S_{i}=Q_{1} \times Q_{2} \ldots \times Q_{i}
$$

"Because they have not yet reached the "end of interval" age, or they have died from another cause.

\section{RESULTS}

The average age $( \pm S D)$ of unaffected carriers included in this study is lower than the average age at disease onset of affected carriers $(49.1 \pm$ 14.9 versus $58.5 \pm 10.0$ years, $p<0.01$ ), a common finding in the study of late onset genetic diseases.

Figure 1 shows that age at disease onset is quite variable, ranging from 40 to 85 years, and that those at risk (unaffected carriers of the mutation) also have a wide age range $(<30$ to 85 years). In fact, the oldest unaffected carrier is equal in age to the oldest reported CJD patient (i.e., 85 years), implying an apparent incomplete penetrance.

Table 1 was used to calculate survival probabilities. The greatest proportion of deaths due to CJD occurred within the third and fourth intervals, or the fifth and sixth decades of life. The cumulative probability of a mutation carrier surviving to the end of the $i^{\text {th }}$ interval without developing CJD $\left(S_{i}\right)$, is maximum at the first interval because no individuals have died of CJD before age 30 , and minimum at the last interval because almost all have died by that time.

Since $S_{i}$ is the probability of surviving to the end of each interval, $1-S_{i}$ is the probability of developing and dying with CJD. Thus, a muta- tion carrier has a probability of 0.23 of surviving to age 70 (the end of the fifth interval) without developing CJD, or a $77 \%$ chance of developing CJD if the subject survives to age 70 . A sigmoidal curve demonstrating this age dependency is generated when disease risk $\left(1-S_{i}\right)$ is plotted against age, as in Fig. 2. Once the individual passes 80 years (enters the seventh interval) disease probability approaches unity.

\section{DISCUSSION}

We have used a life table method of actuarial analysis to determine the phenotypic penetrance of the E200K mutation of the PrP gene in a cohort of 13 Libyan Jewish families. The estimates of penetrance calculated with this method are significantly higher than a previous estimate (9). This difference reflects the ability of the life table method to predict more accurately penetrance of a late onset disease in that (i) it accounts for death due to other disease, and (ii) it accounts for the fact that mutation carriers in such a disease have a low risk of manifesting symptoms until they pass the "at risk age interval", after which time the risk of disease progressively increases. 


\section{Age Distribution of PrP-E200K Carriers}

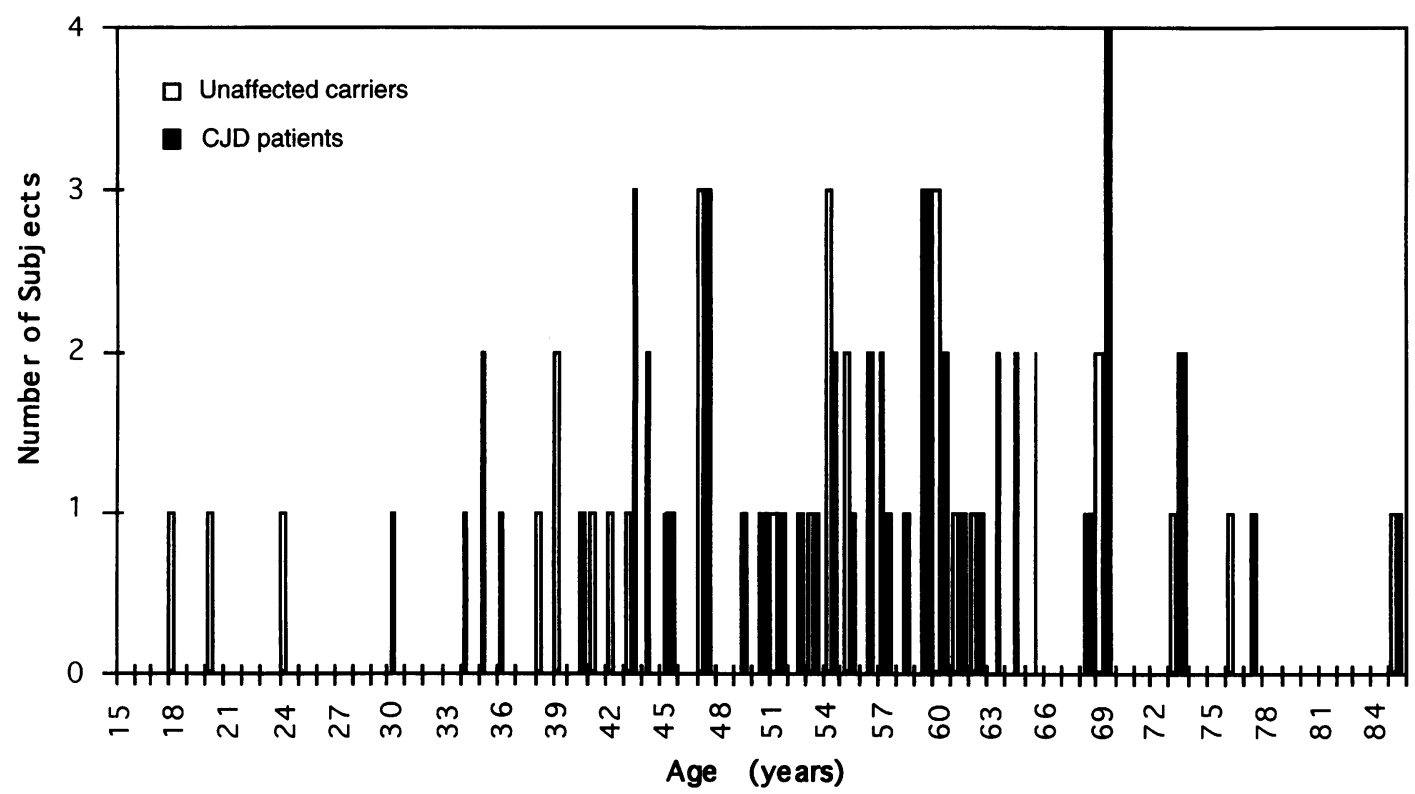

FIG. 1. Age distribution of unaffected and affected carriers of the E200K mutation in a population of Libyan Jews

Our analysis demonstrates that the penetrance of the E200K mutation of the PrP gene is age dependent. We calculated the penetrance to be as low as $1 \%$ at age 40 , which increases sigmoidally with age and approaches $100 \%$, provided the mutation carrier lives past the age of 80. Clearly, these data argue that the presence of the mutation is sufficient for development of disease.

Review of other known mutations of the PrP gene indicates that the wide range of age at disease onset is not restricted to the E200K mutation. The P102L mutation has been reported in patients presenting with disease as early as age 23 and as late as age $61(2,20)$, while the age at onset with the D178N mutation ranges from the teens to the 70s (21). Similarly, the V210I mutation has been found in healthy carriers as old as 82 years (22). Although specific penetrance determination for these mutations has not been reported, this disparity in age at onset among the various prion diseases may lead to the same inappropriate conclusions regarding penetrance as were made with the E200K mutation. Analysis of these other mutations by a life table method will likely demonstrate a similar age-dependent nature with eventual complete penetrance.

This age-related incidence seen with prion disease is strikingly similar to that observed with other neurodegenerative diseases, including Parkinson's disease, amyotrophic lateral sclerosis, Huntington's disease, and particularly Alzheimer's disease. The risk of Alzheimer's disease has

\section{Probability of CJD in E200K Carriers}

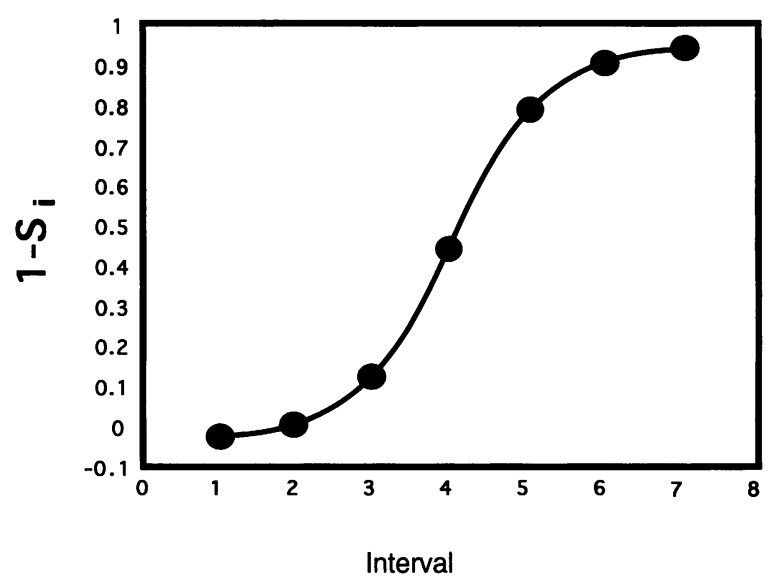

FIG. 2. Cumulative probability of developing CJD $\left(1-S_{i}\right)$ as a function of age in the PrPE200K carriers

The interval corresponds to the age intervals detailed in Table 1. 
been estimated to be $3 \%$ at age $65,19 \%$ at age 75 , and almost $50 \%$ by age 85 (23). More recent studies have shown that the apolipoprotein $\mathrm{E}$ (apoE) isoform determines the age at onset of Alzheimer's disease (24-28). The $\varepsilon 4$ isotype is associated with the earlier age at onset, while the $\varepsilon 2$ and $\varepsilon 3$ isotypes are found in patients with later onset of disease. The apoE isotype has also been reported to influence the age at onset of prion disease (29), but multiple reports have failed to confirm that assertion $(26,30-32)$. The apoE isotype does not correlate with the age at onset of CJD for the population of Libyan Jews included in this study (A. Ben Yehuda, unpublished data).

of note, familial forms of all the neurodegenerative diseases noted above are autosomal dominant disorders $(33,34)$. Like the prion diseases where the pathogenic isoform of the prion protein, $\operatorname{PrP}^{\mathrm{Sc}}$, accumulates and produces cellular dysfunction (35), these disorders will probably be found to be associated with proteins that act as "negative dominant" factors. The mechanism by which the expanded polyglutamine segment of the Huntington's protein produces CNS degeneration is unknown; however, the length of the triplet CAG repeat encoding glutamine correlates inversely with the age at onset of Huntington's disease (36).

Homozygosity at the polymorphic codon 129 of the PrP gene has been reported to increase susceptibility to sporadic (37) and iatrogenic (38) CJD in Caucasians but not in Asians (39). Homozygosity at codon 129 has also been reported to decrease the age at onset of some inherited prion diseases but not others (40-42). The codon 129 polymorphism was not found to influence age at onset among Libyan Jews carrying the E200K mutation (18).

A caveat of the study described here lies in our inability to detect CJD in all of its forms. There are several reports of protracted prion disease for many years and in the case of an amber mutation (Y145Stop), a 20-year clinical course was reported (43). This prolonged course implies that clinical assessment may be inadequate in detecting prion disease; how often this is the case remains to be determined (44). Recently, it was reported that carriers of the F198S mutation in the PrP gene, who were considered to be neurologically "normal", were found to perform significantly poorer than noncarriers in detailed neurocognitive testing, implying a subclinical effect of the mutation in many carriers prior to the onset of overt clinical illness (45). Thus, early manifestations of CNS dysfunction may often escape clinical detection, which influences the "apparent penetrance" of disease.

\section{ACKNOWLEDGMENTS}

This work was supported by grants from the National Institutes of Health (NS14069, AG08967, AG02132, NS22786 and AG10770) and the American Health Assistance Foundation, the Israeli Academy of Sciences (R.G.), and a gift from the Sherman Fairchild Foundation. Support was also provided in part by the Howard Hughes Medical Institute (J.A.M.).

\section{REFERENCES}

1. Prusiner SB. (1991) Molecular biology of prion diseases. Science 252: 1515-1522.

2. Hsiao K, Baker HF, Crow TJ, et al. (1989) Linkage of a prion protein missense variant to Gerstmann-Sträussler syndrome. Nature 338: 342-345.

3. Goldfarb LG, Mitrova E, Brown P, Toh BH, Gajdusek DC. (1990) Mutation in codon 200 of scrapie amyloid protein gene in two clusters of Creutzfeldt-Jakob disease in Slovakia. Lancet 336: 514-515.

4. Hsiao K, Meiner Z, Kahana E, et al. (1991) Mutation of the prion protein in Libyan Jews with Creutzfeldt-Jakob disease. N. Engl. J. Med. 324: 1091-1097.

5. Kahana E, Zilber N, Abraham M. (1991) Do Creutzfeldt-Jakob disease patients of Jewish Libyan origin have unique clinical features? Neurology 41: 1390-1392.

6. Kahana E, Milton A, Braham J, Sofer D. (1974) Creutzfeldt-Jakob disease: Focus among Libyan Jews in Israel. Science 183: 90-91.

7. Herzberg L, Herzberg BN, Gibbs Jr CJ, Sullivan W, Amyx H, Gajdusek DC. (1974) Creutzfeldt-Jakob disease: Hypothesis for high incidence in Libyan Jews in Israel. Science 186: 848.

8. Gabizon R, Rosenman H, Meiner $\mathrm{Z}$, et al. (1994) Mutation in codon 200 and polymorphism in codon 129 of the prion protein gene in Libyan Jews with Creutzfeldt-Jakob disease. Philos. Trans. R. Soc. Lond. Biol. 343: 385-390.

9. Goldfarb LG, Brown P, Mitrova E, et al. (1991) Creutzfeldt-Jacob disease associated 
with the PRNP codon $200^{\text {Lys }}$ mutation: An analysis of 45 families. Eur. J. Epidemiol. 7: 477-486.

10. Diringer H. (1991) Transmissible spongiform encephalopathies (TSE) virus-induced amyloidoses of the central nervous system (CNS). Eur. J. Epidemiol. 7: 562-566.

11. Kimberlin RH. (1990) Scrapie and possible relationships with viroids. Semin. Virol. 1: 153-162.

12. Chesebro B. (1992) PrP and the scrapie agent. Nature 356: 560.

13. Chesebro B, Caughey B. (1993) Scrapie agent replication without the prion protein? Curr. Biol. 3: 696-698.

14. Rimm AA, Hartz AJ, Kalbfleisch JH, Anderson AJ, Hoffman RG. (1980) Basic Biostatistics in Medicine and Epidemiology. Appleton-Century Crofts, New York.

15. Easton DF, Ponder MA, Cummings $\mathrm{T}$, et al. (1989) The clinical screening and age-at-onset distribution for the MEN-2 syndrome. Am. J. Hum. Genet. 44: 208-215.

16. Ponder BAJ, Coffey R, Gagel RF, et al. (1988) Risk estimation and screening in families of patients with medullary thyroid carcinoma. Lancet 1(8582): 397-400.

17. Chapman J, Ben-Israel J, Goldhammer Y, Korczyn AD. (1994) The risk of developing Creutzfeldt-Jakob disease in subjects with the PRNP gene codon 200 point mutation. Neurology 44: 1683-1686.

18. Gabizon R, Rosenmann $\mathrm{H}$, Meiner $\mathrm{Z}$, et al. (1993) Mutation and polymorphism of the prion protein gene in Libyan Jews with Creutzfeldt-Jakob disease. Am. J. Hum. Genet. 33: 828-835.

19. Newcombe RG. (1981) A life table for onset of Huntington's chorea. Ann. Hum. Genet. 45: 375-385.

20. Baker HF, Ridley RM, Crow TJ. (1985) Experimental transmission of an autosomal dominant spongiform encephalopathy: Does the infectious agent originate in the human genome? Br. Med. J. 291: 299-302.

21. Brown P, Goldfarb LG, Kovanen J, et al. (1992) Phenotypic characteristics of familial Creutzfeldt-Jakob disease associated with the codon $178^{\text {Asn }}$ PRNP mutation. Ann. Neurol. 31: 282-285.

22. Pocchiari $M$, Salvatore $M$, Cutruzzola $F$, et al. (1993) A new point mutation of the prion protein gene in familial and sporadic cases of Creutzfeldt-Jakob disease. Ann. Neurol. 34: 802-807.
23. Evans DA, Funkenstein HH, Albert MS, et al. (1989) Prevalence of Alzheimer's disease in a community population of older personsHigher than previously reported. J. Am. Med. Assoc. 10: 2551-2556.

24. Saunders AM, Strittmatter WJ, Schmechel D, et al. (1993) Association of apolipoprotein E allele $\varepsilon 4$ with late-onset familial and sporadic Alzheimer's disease. Neurology 43: 1467-1472.

25. Strittmatter WJ, Saunders AM, Schmechel D, et al. (1993) Apoliprotein E: High-avidity binding to $\beta$-amyloid and increased frequency of type 4 allele in late-onset familial Alzheimer disease. Proc. Natl. Acad. Sci. U.S.A. 90: 1977-1981.

26. Saunders AM, Schmader K, Breitner JCS, et al. (1993) Apolipoprotein E $\varepsilon 4$ allele distributions in late-onset Alzheimer's disease and in other amyloid-forming diseases. Lancet 342: 710-711.

27. Corder EH, Saunders AM, Strittmatter WJ, et al. (1993) Gene dose of apolipoprotein E type 4 allele and the risk of Alzheimer's disease in late onset families. Science 261: 921923.

28. Roses $A D$, Saunders AM, Strittmatter WJ, Schmechel DE, Pericak-Vance MA, Hyman B. (1994) Apolipoprotein E in CreutzfeldtJakob disease. Lancet 345: 69. Letter.

29. Amouyel P, Vidal O, Launay JM, Laplanche JL. (1994) The apolipoprotein E alleles as major susceptibility factors for CreutzfeldtJakob disease. Lancet 344: 1315-1318.

30. Kitamoto T, Tateishi J. (1994) Human prion diseases with variant prion protein. Philos. Trans. R. Soc. Lond. Biol. 343: 391-398.

31. Zerr I, Helmhold M, Weber T. (1994) Apolipoprotein $\mathrm{E}$ in Creutzfeldt-Jakob disease. Lancet 345: 68-69. Letter.

32. Dranovsky A, Goldfarb L, Gajdusek DC, Goldgaber D. (1995) Apolipoprotein E $\varepsilon 4$ allele does not correlate with amyloid plaques in transmissible spongiform encephalopathies. Amyloid: Int. J. Exp. Clin. Invest. 2: $39-41$.

33. Rosen DR, Siddique $T$, Patterson $D$, et al. (1993) Mutations in $\mathrm{Cu} / \mathrm{Zn}$ superoxide dismutase gene are associated with familial amyotrophic lateral slerosis. Nature 362: 5962.

34. St. George-Hyslop P, Haines J, Rogaev E, et al. (1992) Genetic evidence for a novel familial Alzheimer's disease locus on chromosome 14. Nat. Genet. 2: 330-334. 
35. Prusiner SB. (1994) Biology and genetics of prion diseases. Annu. Rev. Microbiol. 48: 655685.

36. Kieburtz K, MacDonald $M$, Shih $C$, et al. (1994) Trinucleotide repeat length and progression of illness in Huntington's disease. $J$. Med. Genet. 31: 872-874.

37. Palmer MS, Dryden AJ, Hughes JT, Collinge J. (1991) Homozygous prion protein genotype predisposes to sporadic Creutzfeldt-Jakob disease. Nature 352: 340-342.

38. Collinge J, Palmer MS, Dryden AJ. (1991) Genetic predisposition to iatrogenic CreutzfeldtJakob disease. Lancet 337: 1441-1442.

39. Tateishi J, Kitamoto T. (1993) Developments in diagnosis for prion diseases. Br. Med. Bull. 49: 971-979.

40. Petersen RB, Tabaton $M$, Berg $L$, et al. (1992) Analysis of the prion protein gene in thalamic dementia. Neurology 42: 1859-1863.

41. Baker HF, Poulter M, Crow TJ, Frith CD,
Lofthouse R, Ridley RM. (1991) Amino acid polymorphism in human prion protein and age at death in inherited prion disease. Lancet 337: 1286.

42. Poulter M, Baker HF, Frith CD, et al. (1992) Inherited prion disease with 144 base pair gene insertion. 1. Genealogical and molecular studies. Brain 115: 675-685.

43. Kitamoto T, Iizuka R, Tateishi J. (1993) An amber mutation of prion protein in Gerstmann-Sträussler syndrome with mutant PrP plaques. Biochem. Biophys. Res. Commun. 192: 525-531.

44. Collinge J, Owen F, Poulter H, et al. (1990) Prion dementia without characteristic pathology. Lancet 336: 7-9.

45. Unverzagt FW, Farlow MR, Dlouhy SR, et al. (1994) Presymptomatic neuropsychological deficits in Gerstmann-Sträussler-Scheinker disease. Ann Neurol 36: 272. Abstract.

Contributed by S. B. Prusiner on June 26, 1995. 